\title{
NASA AND SUPERALLOYS: A CUSTOMER, A PARTICIPANT, AND A REFEREE
}

\author{
Michael. V. Nathal \\ National Aeronautics and Space Administration, Glenn Research Center, Cleveland, OH 44135 USA
}

Keywords: superalloys, shape memory alloys, Stirling engines, power systems

\begin{abstract}
NASA has had a long history of research and development in the field of superalloys. These efforts have continued today, where the latest advancements in turbine disk and blade technologies are being developed Although NASA does support military flight systems, it's predominant role is in supporting civilian air transportation systems, and thus has goals for improving fuel efficiency, emissions, noise, and safety of today's aircraft. NASA has traditionally served several distinct but complimentary roles as participants in multi-disciplinary research teams, as customers who fund research and development efforts at industry and universities, and as referees who can address broad issues that affect the entire aeronautics community. Because of our longer range viewpoint, we can take on higher risk, higher reward research topics. NASA can also serve as an intermediary between the basic research performed primarily at universities and the development efforts emphasized by industry. By interacting with individual companies, NASA can identify areas of general interest and problems common to a large portion of the aeronautics community, and devise programs aimed at solving these problems. In space missions, NASA is a direct customer responsible for developing vehicles. In the case of the Space Shuttle, NASA has worked with various contractors to design and build numerous components out of superalloys. Another fascinating area for the use of superalloys is in power systems for long life applications in space. Potential missions include providing electric power for deep space missions, surface rovers, including lunar and Mars, and stationary power generators on the lunar surface.
\end{abstract}

\section{Introduction}

This paper addresses the symposium theme of "the perspective of the customer" and NASA's role in the superalloy community. The title was chosen as not only a description of NASA's multiple roles but as tribute to one of the first technical papers the author read at the start of his graduate thesis research. Fittingly, "Cobalt and Sigma: Participant, Spectator, or Referee?" by Lund, Woulds and Hockin [1] was published in the first Superalloys Symposium in 1968. Just as the role of cobalt in superalloys can change based on the presence or absence of various alloying elements, the role of NASA can change depending on a variety of technical and programmatic functions. NASA has traditionally assumed roles as participants in multi-disciplinary research teams, as customers who fund research and development efforts at industry and universities, and as referees who can address broad issues that affect the entire aeronautics community. In broad terms, NASA's main mission of Space Exploration has always been combined with an Aeronautics mission that is less well known to the general public. However, the Aeronautics mission is more directly aligned with the general superalloys community that is represented at this symposium.

\section{NASA and Aeronautics}

In contrast to the Department of Defense, which is responsible for developing specific vehicles, NASA's role in the Aeronautics arena has traditionally been viewed as providing fundamental knowledge and advanced concepts to the broad aeronautics community. Although NASA does support military flight systems, its major responsibility is supporting civilian air transportation systems, and thus has goals for improving fuel efficiency, emissions, noise, and safety of today's aircraft. NASA has traditionally approached research goals by a combination of inhouse research, contracts with industry, and grants with universities.

Because of a longer range viewpoint, NASA can take on higher risk, higher reward research topics. This is accomplished through a balanced research portfolio that includes both evolutionary advances in superalloys but also more revolutionary "alternate materials." Second, NASA can serve as an intermediary between the basic research performed primarily at universities and the development efforts emphasized by industry. By interacting with individual companies, NASA can identify areas of general interest and problems common to a large portion of the aeronautics community, and devise programs aimed at solving these problems. For example, programs directed at the conservation of strategic metals [2], and at improving the life prediction of disk alloys have been pursued. The guiding philosophy is to increase the technology readiness level to reduce risk to the point that industry would continue further development with their own funds. Another aspect, not to be overlooked, is that we attach importance to training the next generation of students. To this end, a variety of undergraduate internships, university research grants, summer faculty fellowships, and graduate student fellowships are awarded each year. In many cases, residency of graduate students for periods ranging from a summer to an entire year is used to supplement the graduate research and allows the university to take advantage of NASA facilities.

The Glenn Research Center, formerly known as Lewis Research Center, has been active in the area of Ni-base alloys for turbine engine components since the 1950's. NASA researchers have been part of several major national initiatives, including oxide dispersion strengthened alloys, single crystal superalloys, powder metallurgy disk alloys, directionally solidified eutectics, and metal matrix composites. In the late 1980's, the predominant NASA view was that superalloy technology was mature, and that significant advances were more likely to be achieved via replacing superalloys with ceramics, metal matrix composites, and intermetallics. This view, shared by other government agencies, resulted in very large efforts to develop and demonstrate alternate materials for aerospace applications. In many cases, successful technical demonstrations via ground based engine testing were achieved, but even today the use of these alternatives is quite 
limited. For example, metal matrix composites were successfully demonstrated in ground-based engine tests a number of times [3] but are not widely employed. As an outcome of these limited success stories, a more tempered viewpoint has evolved, where the still-impressive pay-offs for these alternative materials is combined with a more realistic assessment of the risks and the patience required to mitigate these risks.

A more balanced portfolio of high risk/high payoff materials combined with materials with more modest but achievable payoffs is now in place. In terms of alternate materials, NASA is primarily focusing on ceramics and CMC's, whereas MMC's and intermetallics research is now considerably reduced, with only TiAl given much emphasis. As an example of exploring new ideas, NASA recently began pursuing a change of strategy for alternative means of achieving performance gains through improved materials. In the past, the idea of improved capability in an engine was addressed through attempting to increase the capability of the material itself. Thus, improved temperature capability, (i.e., both mechanical properties and environmental resistance) and/or reduced weight were aimed at improved superalloys or alternative materials. As an alternative, the use of today's superalloys in light weight architectures can achieve significant weight savings while still maintaining the positive attributes of the superalloys. Lattice block superalloys [4] in particular have shown very good strength and damage tolerance in a light weight architecture. Figure 1 shows an example lattice block that weighs only $15 \%$ of a solid plate of the same external dimensions. In this case, NASA's role was to identify some promising Navy-funded research on lattice block materials and to establish the feasibility for extending that work to high temperature alloys. Preliminary work established that investment casting is a valid method for producing economical lattice blocks, and that the mechanical properties of lattice blocks made from both IN718 and Mar-M247 are close to expectations based on normal handbook values. It is our current view that the next step needed to implement lattice block technology would require improved design tools needed for optimization of the lattice structure. In addition, the next step in development should be accomplished through collaboration with industry partners in order to assure that the major relevant issues are addressed.

Additional work [5] has been initiated in exploring the fundamental properties of superalloy foams, such as that illustrated in Figure 2. Metallic foams can offer promising performance gains by combining acoustic absorption with structural functions in sandwich concepts that could be used in fan, compressor, and turbine cases.

One additional strategy that has significant potential is the ability to use "smart materials" to achieve performance improvements. Systems and design studies have shown that substantial gains in engine noise, fuel efficiency and emissions can be achieved not just by increasing material properties but by individually optimizing different components for different portions of a flight's mission cycle. Thus, the main structural components remain as superalloys, but they are used in configurations that can take advantage of properties optimized to specific environments. For example, separately optimizing for take-off and cruise portions of a mission requires only small changes to the inlet or exhaust nozzle geometry, airfoil camber, fuel nozzles and mixers, and other components [6]. Additionally, if an engine component can "adapt" to changes in the environment, additional gains can be achieved. An example of this would be active turbine tip
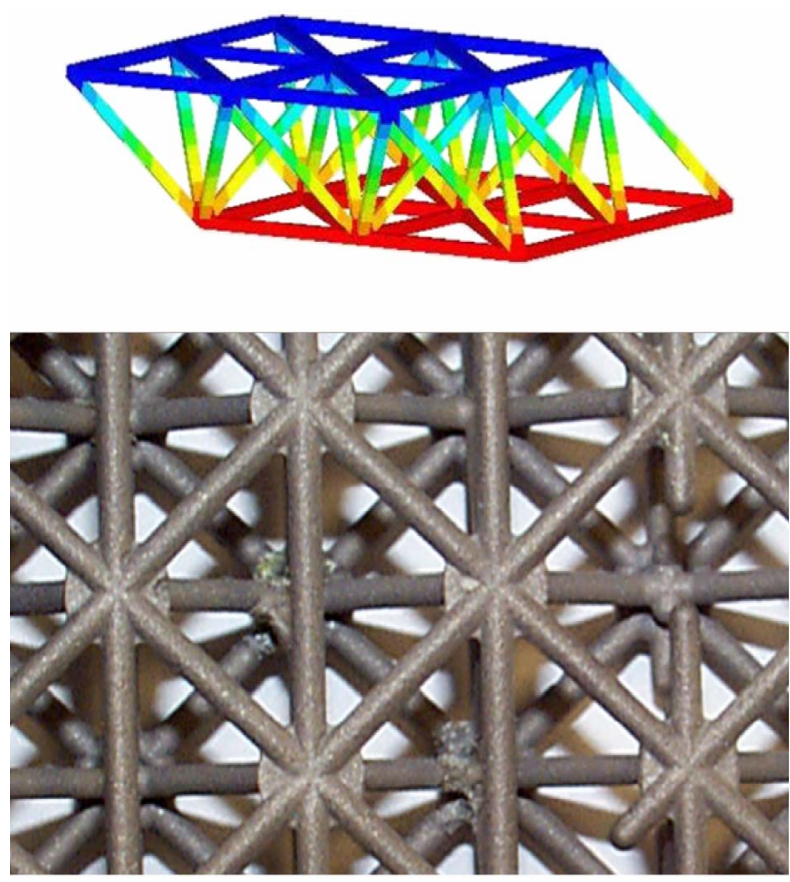

Figure 1. Lattice block superalloys as examples of light weight structural concepts that can save weight without sacrificing the desirable properties of superalloys such as their creep strength and damage tolerance. (a) Three dimensional model of the lattice structure. (b) Photograph of an In718 lattice block casting with $1 \mathrm{~mm}$ diameter ligaments.

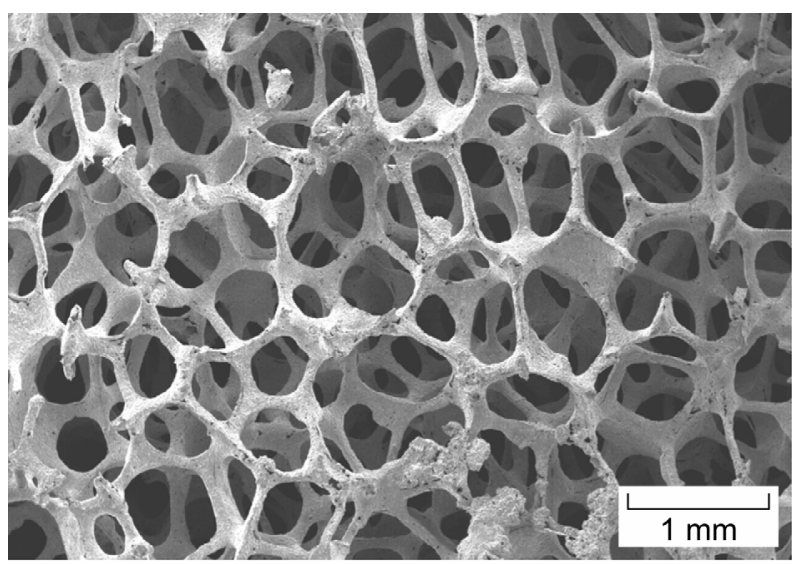

Figure 2. Example of a metallic foam being investigated for turbine engine use. This foam is made of the Co base alloy Haynes 25 and is about 5 percent dense.

clearance control, where tip shrouds could be adjusted to compensate for increased turbine airfoil tip wear or rub [7]. Another example is active flow control. A compressor's aerodynamics can improve efficiency but may be limited by the onset of compressor stall conditions. A strategy of advanced sensors that can detect the onset of incipient stall, which would then trigger small changes to the flow geometry, allows for a compressor that has both improved efficiency plus tolerance against stall conditions [8]. Many of these concepts have been envisioned in the past, but could not be achieved because they relied upon electric, hydraulic or pneumatic 
actuators that brought excessive weight penalties. Our approach currently is to utilize advanced shape memory alloys in order to achieve these breakthroughs. Actuators that utilize a shape memory alloy (SMA) as an actuation mechanism have been shown to have excellent specific force capabilities, along with additional advantages of low part count, very small geometric footprint requirements, and low power requirements [9]. NASA has instituted a relatively large research program aimed at implementing such devices. The main problem limiting the use of commercial shape memory alloys is their temperature capability, which is limited to roughly 50 to $100{ }^{\circ} \mathrm{C}$. We have identified alloys based on commercial Nitinol alloys with substantial ternary alloying additions that show exceptional promise for use temperatures exceeding $400^{\circ} \mathrm{C}$. In addition to the alloy development, processing development has also been addressed, and commercially useful forms of plate, rod, and wire have been produced from these new high temperature alloys. The understanding of the basic mechanisms of how SMA's behave is another critical issue, as the current state of knowledge is insufficient for complete design of robust actuators, as well as the prediction of their useful life when exposed to a number of potential durability limits, including creep, fatigue, and oxidation resistance. Several high temperature alloys have already been identified [10], and have been used in successful bench top component demonstrations, including an adaptive inlet, a high temperature variable geometry chevron, and compressor flow control.

Utilization of shape memory alloys as actuators is shown in simple form as a weight suspended from an SMA wire, Figure 3. As heat is applied to the SMA wire, typically through selfresistance heating, the wire contracts due to the shape memory effect, and the weight is lifted, thus performing work. Work is defined by the mass of the weight times the distance moved, and is the critical property for SMA development. Cooling the wire causes the weight to be returned to the lower position. Figure 4 displays the thermo-mechanical test employed that mimics actuator performance in a mechanical testing frame. A load is applied at low temperature, and maintained as the temperature is cycled through the martensite/austenite transformation. Again, the applied stress multiplied by the transformation strain defines the work capability of the alloy. This "load bias" test is used to screen alloys during development, with results of a three year development program demonstrating that significant advancements in alloy capability are feasible. Commercially available NiTi alloys have high work output but are limited to temperatures below $100{ }^{\circ} \mathrm{C}$. The newly developed alloys, formed by ternary and quaternary additions to $\mathrm{NiTi}$, are exhibiting temperature capability between 200 and $400{ }^{\circ} \mathrm{C}$, while still maintaining high work capability levels.

The recognition within NASA that substantial and valuable improvements in superalloy capability are still feasible began to increase in the early 90's with the onset of the Enabling Propulsion Materials (EPM) project that was funded under the High Speed Research program. The level of risk for a high speed civil transport was deemed high enough that a high level of technology readiness was chosen as the program goal. This necessitated a concentrated effort in a few key technologies, and research into improved turbine disk and airfoil superalloys, along with large TiAl structural components and ceramic combustors was initiated. The goal of a high technology readiness level resulted in a decision to form integrated teams with NASA and engine company researchers. Although the High Speed Research

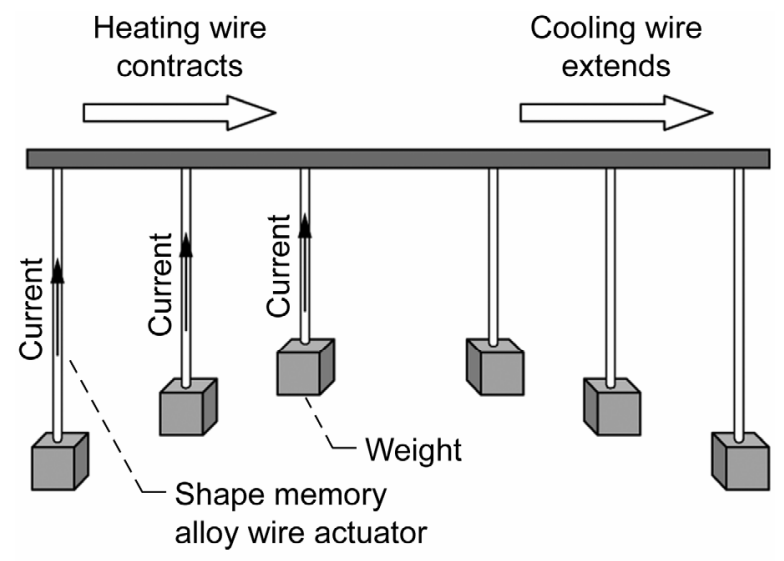

Figure 3. Schematic of the use of a shape memory alloy as an actuator. As heat is applied to the SMA, it contracts and performs work.

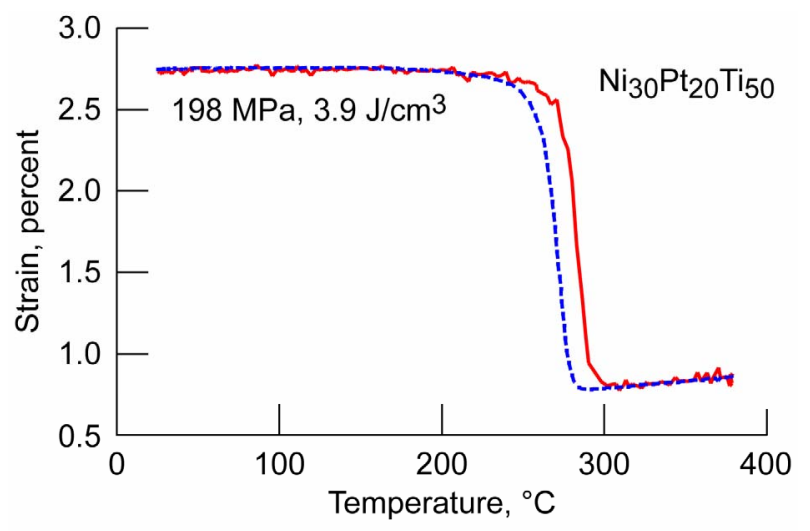

Figure 4. The thermo-mechanical test employed that mimics actuator performance in a mechanical testing frame. A load is applied at low temperature, and maintained as the temperature is cycled through the martensite/austenite transformation. In this example, the experimental SMA has an actuation temperature of about $250{ }^{\circ} \mathrm{C}$, and a work output of $3.9 \mathrm{~J} / \mathrm{cm}^{3}$.

Program was eventually cancelled, some of the materials technology emerged as applicable across several vehicle classes, not just a supersonic transport. The turbine disk alloy ME3 $(\mathrm{Ni}-20.6 \mathrm{Co}-13 \mathrm{Cr}-3.4 \mathrm{Al}-3.7 \mathrm{Ti}-2.4 \mathrm{Ta}-0.9 \mathrm{Nb}-2.1 \mathrm{~W}-$ $3.8 \mathrm{Mo}$ ) [11] is the most notable outcome of the EPM program, and has been introduced into commercial engines. The $\mathrm{SiC} / \mathrm{SiC}$ ceramic matrix composite technology, particularly advances that lead to the introduction of the Sylramic fiber [12], was another breakthrough that has continued to influence subsequent programs [13].

More recently, increased capability in superalloys has been directly linked to NASA goals for improved emissions and safety. In many cases the research budget to accomplish these gains has been quite modest, especially in comparison to EPM and the larger military engine demonstration programs. Research continues on advanced disk alloys, with one focus on improved alloy capability, achieved by a combination of new alloys based on variations of the ME3 alloy composition, as well advanced processing such as dual alloy heat treatment [14]. The focus on aircraft safety has translated into 
research on issues that limit durability of these new alloys in their higher temperature regimes. Because the alloys are being used at temperatures in excess of $650{ }^{\circ} \mathrm{C}$, new failure mechanisms become more important, such as environmental attack, microstructural stability, and fatigue cycles that incorporate sustained dwells. Whereas each individual alloy may have specific responses that are dependent on a given engine design, the goal of the NASA program will be to identify and model the mechanisms such that reliable durability predictions can be made, and that these models can be applied to specific companies to apply to their specific situation.

Examples of turbine disk alloy durability investigations include work presented in past Superalloys symposia. Work on the use of dual alloy heat treatments was taken from coupon scale through subscale disk processing and several disk spin tests. The spin tests verified the life and deformation models, as well as the integrity of the fine grain/coarse grain transition area [14]. The effects of environmental exposures on fatigue life [15], and microstructural effects on fatigue crack growth [16] are other examples. The tracking of size, shape, and location of non-metallic inclusions has also been investigated [17]. Recent results, shown in Figure 5, demonstrate that the low cycle fatigue response of disk alloys requires improved understanding. Unusual responses of early failure in the fatigue cycles that included an extended tensile dwell, especially in the presence of a notch, have been observed [18]. The influence of microstructure on this effect is quite prominent, and is a subject of ongoing research. The ability to accurately model microstructural evolution in these alloys is also recognized as a key issue.

The EPM program also pursued the development of a $4^{\text {th }}$ generation single crystal alloy. The alloy EPM102 (Ni - 16.5Co - 2.0Cr $5.5 \mathrm{Al}-8.2 \mathrm{Ta}-6.0 \mathrm{~W}-6.0 \mathrm{Re}-2.0 \mathrm{Mo}$ ) was developed with exceptional creep life customized to the supersonic mission, which emphasized extended dwells at relatively high temperatures [19]. Although EPM102 also has potential for use in advanced military and subsonic commercial engines, the potential is limited by its very high density, as well as compromises in environmental resistance and microstructural stability. Since the trends in alloy design have shown a strong correlation of improved creep strength with higher alloy density, a common perception has been to view superalloys as having reached their ultimate limits. Thus again, ceramics and high temperature intermetallics such as silicides have been proposed. These alternate materials can achieve both lower density and increased strength at very high temperatures, although many of these materials lack environmental resistance and all lack toughness. Faced with this quandary, a new NASA research project was initiated, to establish feasibility of a different materials development strategy. The new approach aimed at designing a single crystal superalloy with significantly lower density compared to $3^{\text {rd }}$ and $4^{\text {th }}$ generation alloys. This immediately proves advantageous over the ceramic and intermetallic alternate materials, because their low toughness is difficult if not impossible to mitigate. If necessary, the alloy oxidation resistance could also be reduced somewhat, as a reliance on a coating was deemed a more acceptable risk than the low toughness of the alternate materials. Additional constraints on the level of exotic elements such as Re and $\mathrm{Ru}$ were also installed, in order to improve on the microstructural stability and cost issues inherent in $3^{\text {rd }}$ generation airfoil alloys. Thus, a program was launched to maximize alloy creep at densities not to exceed $2^{\text {nd }}$ generation levels of approximately $8.7 \mathrm{gm} / \mathrm{cm}^{3}$. As can be seen in Figure 6, alloys with attractive balance of properties have been achieved [20]. The next step in this program would be to collaborate with engine company customers to apply these new alloy concepts to their specific needs.
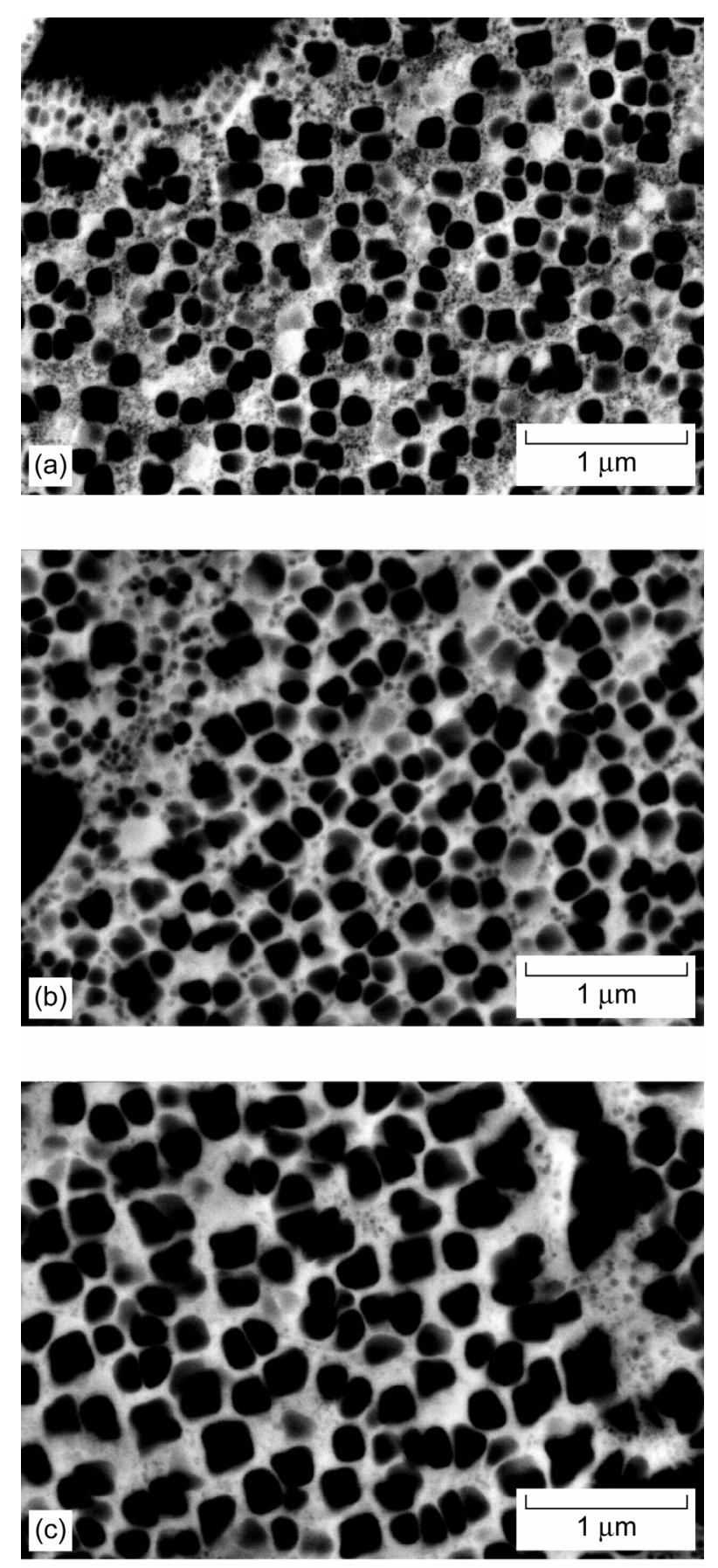

Figure 5. Microstructures of a new disk alloy LSHR as a function of heat treatment. (a) Subsolvus solution treated/ oil quenched, and single step aged at $775^{\circ} \mathrm{C}$. (b) Subsolvus solution treated/oil quenched, and double aged at 855 and $775^{\circ} \mathrm{C}$. (c) Supersolvus solution treated/ air cooled, and single step aged at $775^{\circ} \mathrm{C}$. Heat treatments (a) and (c) produce creep lives roughly ten times longer than (b), but are more susceptible to low lives under dwell fatigue testing in the presence of a notch. 

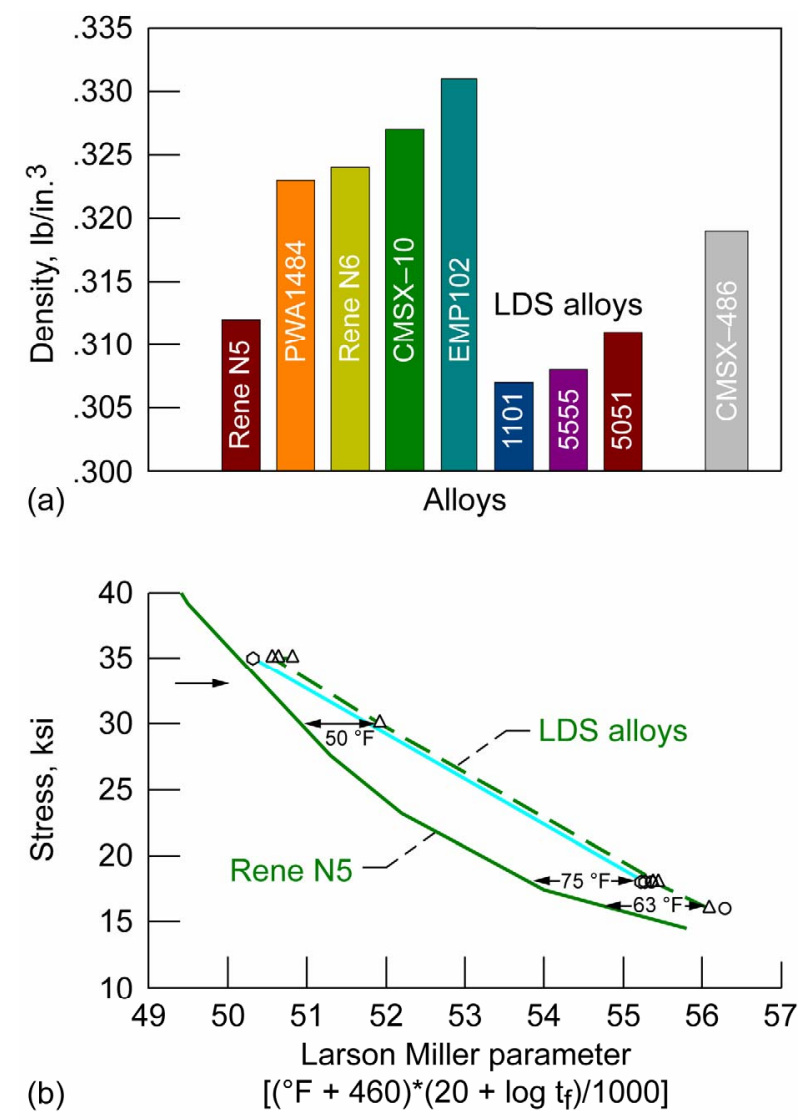

Figure 6. Results of an exploration of new alloy design space for single crystal turbine blades where low alloy density was emphasized. The LDS alloys developed have (a) significantly lower densities than many 3rd and 4th generation alloys and (b) attractive creep-rupture lives.

\section{NASA and Space}

Probably less well known are the applications of superalloys to space missions, where NASA is a direct customer responsible for developing vehicles.

In the case of the Space Shuttle, NASA has worked with various contractors to design and build numerous components out of superalloys. Marshall Space Flight Center has the responsibility for the design and development of the Shuttle engines. The Space Shuttle is now approaching 30 years in service, and although the design is substantially unchanged, many improvements have been implemented over time.

Superalloys such as IN718, IN100 and Mar-M246 are used in various places throughout the Space Shuttle, including the fuel and oxygen turbopumps as well as backing structures within the wings. IN718 is used in numerous components, ranging from the tail rudder speed brake to the wing's backing structure for the reinforced carbon/carbon outer shell. In addition, IN718 accounts for more than half of the total weight of the Shuttle's main engine, including critical components in the fuel and oxygen turbopumps. IN718 is also used for the pressure vessels of nickel-hydrogen batteries for the International Space Station. More advanced alloys, such as PWA 1484 single crystals, are used in the second generation turbopumps for the main engine. In all these cases, NASA's role as a customer is to ensure proper capability for the components, as well investigate potential development efforts for improved capability. In addition, normal operations related issues need to be addressed by materials applications engineers. For example, substantial pitting in the rudder speed brake panels was discovered during refurbishment activities for the Shuttle in 2003. Work needed to occur to identify the root cause for the pitting, as well as determining the extent of the damage, the risk to the vehicle safety, and potential repair methods [21]. In this effort, the NASA materials engineers were part of the newly formed NASA Engineering Safety Center (NESC) which is intended to provide an independent technical assessment (i.e., as a "referee").

Another fascinating area for the use of superalloys is in power systems for long life applications in space. Potential missions include providing electric power for deep space missions, surface rovers, including lunar and Mars, and stationary power generators on the lunar surface. Versatility to fly all of these missions requires a power system that is compatible for use in environments both with and without atmospheres. As these missions attempt to answer ever more difficult questions on how planets form, or if life or water is present, their power demands grow to accommodate the more sophisticated but power-hungry instrumentation. A reliance on solar power places limits on accessible locations even on the moon, let alone the outer planets. The prime candidate to supply power to deep space missions rely on radioisotope power systems (RPS) to generate power on the order of 10's to 100's of Watts. RPS devices convert the heat from radioactive decay of a material such as plutonium into electric power. Thermoelectric RPS concepts rely on the Seebeck effect, where appropriate materials generate voltage in the presence of a temperature gradient. Thermoelectric devices have powered satellites such as Galileo, launched in 1989 that orbited Jupiter; Ulysses, launched in1990, that is still orbiting the north and south poles of the sun; Cassini-Huygens, launched in 1997, probing Saturn and its moons; and most recently New Horizons, launched in 2006 and scheduled to reach Pluto in 2015 [22].

Newer concepts that provide higher efficiency and thus higher power levels are based on Stirling engine technology [23]. Stirling Radioisotope Generators (SRGs) rely on a closed-cycle piston heat engine to convert the heat to electric power. An attractive feature of the SRG system is that its efficiency of 20 to $35 \%$ would reduce the required amount of radioisotope by a factor of four or more compared to thermoelectric systems. This significantly reduces radioisotope cost, radiological payload, and system cost. These engines have components that are required to operate at temperatures in excess of 650 to $850{ }^{\circ} \mathrm{C}$ for lives up to 20 years. Superalloys are the prime candidates for these components. The desire for $100 \%$ reliability places a premium on the use of well known materials with extensive pedigrees, that allow for accurate life predictions and designs that still require minimum weight. Steady use in the aerospace and land-based power systems allow a large number of superalloys to be considered for RPS components. However, data on superalloy performance for the unique requirements of very long lives in the high vacuum environment of space is not very prevalent. Therefore NASA has programs in place aimed at reducing risk via ensuring that appropriate superalloys are selected, suitable processing and joining methods are developed, and thorough theoretical and experimental evaluations of durability and life are in place. Some of the potential durability issues that need to be 
addressed include long time creep, loss of alloying elements through sublimation, permeation or leaking of the helium working gas, and interdiffusion between alloys of joined subcomponents.

The heart of the Stirling engine is the heater head, Figure 7. This is the pressure vessel that contains the He working gas and the piston that translates within the engine. The wall thickness of the heater head reflects a compromise between the thin wall needed to minimize heat conduction yet still maintain the pressurized gas. Early versions of the heater head were designed to operate at $650{ }^{\circ} \mathrm{C}$ and were designed with IN718. In the case of IN718, testing was required to characterize the creep strength of specific heats procured for flight hardware, particularly in a thin wall configuration. In addition, the life assessment of the heater head could take advantage of the extensive long-term creep database for IN718 from Oak Ridge National Lab. Newer heater head concepts are designed to operate at $850{ }^{\circ} \mathrm{C}$ and utilize Mar-M247 as the structural material [24]. In this case, an equivalent long term database is not available, so the design stresses and failure mechanisms need to be carefully assessed to ensure the 20 year life of the components.

Other missions envisioned by NASA's Exploration Mission Directorate require even more electric power, on the order of 10 to $100 \mathrm{~kW}$. In theses cases, fission nuclear reactors are the more efficient choice. For example, a previously proposed ion-
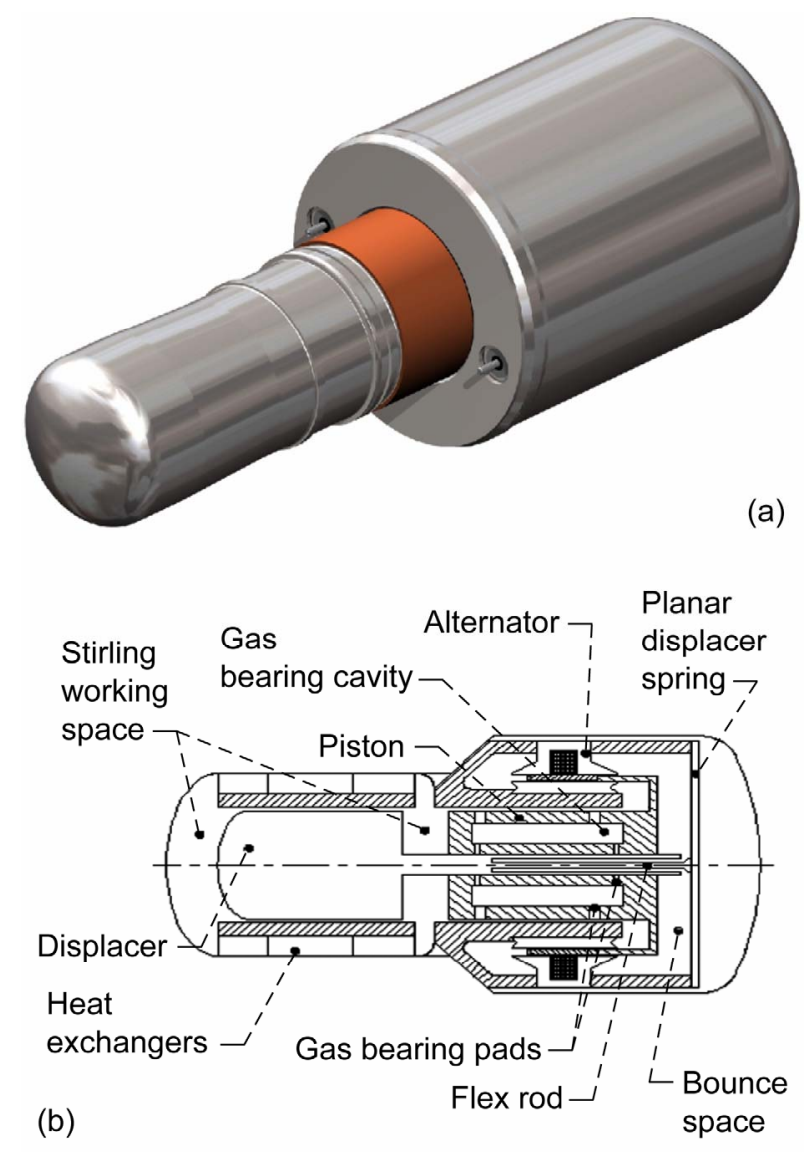

Figure 7. Main components of a Stirling Radioisotope Converter. (a) Perspective view. (b) Longitudinal section showing internal features. propulsion based flagship mission was envisioned to need high power levels to supply not only the instrumentation but also the electric propulsion system. These ion engines would allow for unprecedented maneuverability, allowing the vehicle to orbit several of Jupiter's moons in a defined sequence. Although the large ion-propulsion based vehicles are not under current development, similar high power levels are anticipated for future lunar bases.

Superalloys are envisioned for many components for these systems, particularly in the heat exchangers required to extract and manage the thermal loads. In addition to creep capability, other design criteria include radiation tolerance, manufacturability, compatibility with heat exchanger fluids, and ability to be integrated with higher- and lower-temperature components. NASA's role in these projects has been to ensure that the life requirements can be met, and to identify and/or develop methods to bond superalloys to dissimilar metals. Bonding of superalloys to refractory metals, stainless steel and $\mathrm{Ti}$, combined with the long term stability of the joints, is being pursued by a combination of experiments and modeling [25]. Examples of the some of the interfaces formed between superalloys and refractory metals are shown in Figure 8. Analysis of the reaction zone growth resulted in time/temperature life limits that were used in design trade studies.
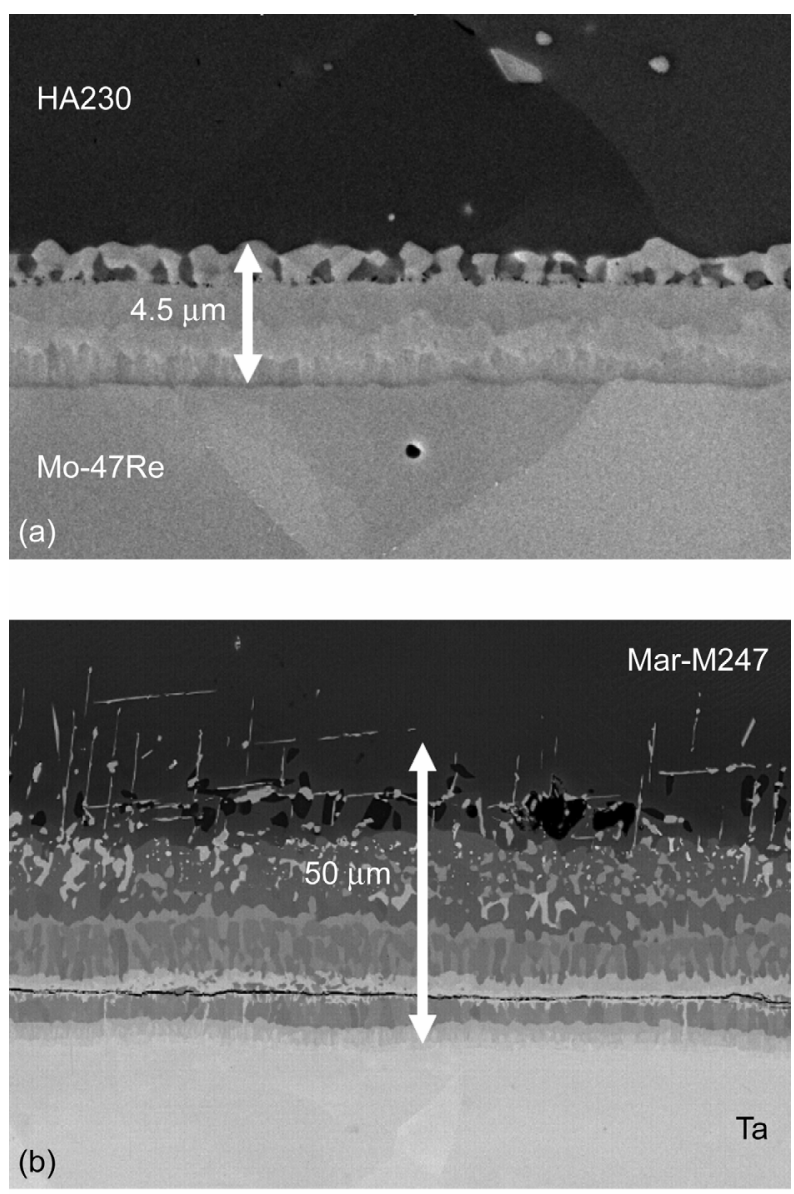

Figure 8. Reaction zones formed between superalloys and refractory metals. (a) Haynes 230 and Mo-47Re alloy couple. (b) Mar-M247 and Ta alloy couple. 


\section{Conclusions}

An overview of NASA efforts in superalloys has been presented. NASA has traditionally served several distinct but complimentary roles as participants in multi-disciplinary research teams, as customers who fund research and development efforts at industry and universities, and as referees who can address broad issues that affect the entire aeronautics community. NASA typically addresses higher risk, higher reward research topics that aim to improve noise, emissions, and safety of commercial aircraft. In space missions, NASA is a direct customer responsible for developing high temperature systems ranging from the Space Shuttle to future planetary probes, surface rovers, and lunar and planetary bases. The strategy to accomplish this wide variety of efforts relies on a strong in-house technical staff capable of both research and development efforts.

\section{References}

1. C.H. Lund, W.J. Woulds, and J. Hockin, Proceeding of the First Int'l Symposium on Structural Stability in Superalloys (Seven Springs, PA: 1968), 25.

2. J.R. Stephens, R.L. Dreshfield, and M.V. Nathal, Refractory Alloying Elements in Superalloys, eds. J.K. Tien and S. Reichman (Metals Park, OH: American Society for Metals, 1984) 31.

3. S.A. Singerman and J.J. Jackson, Superalloys 1996, eds. R.D. Kissenger, D.J. Deye, D.L. Anton, A.D. Cetel, M.V. Nathal, T.M. Pollock, and D.A. Woodford, (Warrendale, PA: TMS, 1996) 579.

4. M.V. Nathal, J.D. Whittenberger, M.G. Hebsur, P. Kantzos, and D.L. Krause, Proceedings of the 10th Int. Symp. on Superalloys, eds. K.A. Green, T.M. Pollock, H. Harada, T.E. Howson, R.C. Reed, J.J. Schirra, and S. Walston, (Warrendale, PA: TMS, 2004) 431.

5. D.L. Sutliff and M.G. Jones, "Proc. 14th AIAA Aeroacoustics Conference" (AIAA Paper 2008-2897, 2008).

6. R. Noebe, D. Gaydosh, S. Padula, A. Garg, T. Biles, and M. Nathal, "Properties and Potential of Two (Ni,Pt)Ti Alloys for Use as High-Temperature Actuator Materials" (Paper presented at the Smart Structures and Materials 2005: Active Materials: Behavior and Mechanics SPIE Conference Proceedings, vol. 5761, 2005), 364-375.

7. J.A. DeCastro, K.J. Melcher, and R.D. Noebe, "Proceedings of the 41st Joint Propulsion Conference" (AIAA Paper 2005-3988, 2005).

8. S. Padula, R.D. Noebe, G. Bigelow, D. Culley, M. Stevens, N. Penney, D.J. Gaydosh, T. Quackenbush, and B. Carpenter Proceedings of AIAA Structures, Structural Dynamics, and Materials Conference (2007).

9. J.H. Mabe, F.T. Calkins, and R.T. Ruggeri, "Smart Structures and Materials 2007 SPIE Conference Proceedings" (SPIE Paper 6525-48, 2007).

10. R. Noebe, S. Padula, G. Bigelow, O. Rios, A. Garg, and B. Lerch, "Smart Structures and Materials 2006 Active Materials: Behavior and Mechanics SPIE Conference Proceedings" (SPIE Paper No. 617010, vol. 6170, 2006).

11. T.P. Gabb, A. Garg, D.L. Ellis and K.M. O'Connor, "Detailed Microstructural Characterization of the Disk Alloy ME3" (NASA/TM-2004-213066, 2004).
12. H.M. Yun and J.A. DiCarlo, Ceram. Eng. Sci. Proc., 20 (1999), 259-272.

13. J.A. DiCarlo, H.M. Yun, G.N. Morscher, and R.T. Bhatt, "SiC/SiC Composites for $1200{ }^{\circ} \mathrm{C}$ and Above," Handbook of Ceramic Composites, ed. N. Bansal (Boston, MA: Kluwer Academic Publishers, 2005), 77-98.

14. J. Gayda, T.P. Gabb, and P.T. Kantzos, Proceedings of the 10th Int. Symp. on Superalloys, eds. K.A. Green, T.M. Pollock, H. Harada, T.E. Howson, R.C. Reed, J.J. Schirra, and S. Walston, (Warrendale, PA: TMS, 2004) 323.

15. T.P. Gabb, J. Telesman, P.T. Kantzos, J.W. Smith, and P.F. Browning, Proceedings of the 10th Int. Symp. on Superalloys, eds. K.A. Green, T.M. Pollock, H. Harada, T.E. Howson, R.C. Reed, J.J. Schirra, and S. Walston, (Warrendale, PA: TMS, 2004) 269.

16. J. Telesman, P. Kantzos, J. Gayda, P.J. Bonacuse, and A. Prescenzi, Proceedings of the 10th Int. Symp. on Superalloys, eds. K.A. Green, T.M. Pollock, H. Harada, T.E. Howson, R.C. Reed, J.J. Schirra, and S. Walston, (Warrendale, PA: TMS, 2004) 215.

17. P. Kantzos, P.J. Bonacuse, J. Telesman, T.P. Gabb, R. Barrie, and A. Banik, Proceedings of the 10th Int. Symp. on Superalloys, eds. K.A. Green, T.M. Pollock, H. Harada, T.E. Howson, R.C. Reed, J.J. Schirra, and S. Walston, (Warrendale, PA: TMS, 2004) 409.

18. J. Gayda, T.P. Gabb, and J. Telesman, "Notch Fatigue Strength of a PM Disk Superalloy" (NASA/TM-2007-215046, 2007).

19. S. Walston, A. Cetel, R.A. MacKay, K. O'Hara, D. Duhl, and R. Dreshfield, Proceedings of the 10th Int. Symp. on Superalloys, eds. K.A. Green, T.M. Pollock, H. Harada, T.E. Howson, R.C. Reed, J.J. Schirra, and S. Walston, (Warrendale, PA: TMS, 2004) 15.

20. R.A. MacKay, T.P. Gabb, J.L. Smialek, and M.V. Nathal, "Low Density, High Creep Resistant Single Crystal Superalloys for Turbine Airfoils" (U.S Patent 7,261,783 B1, Aug. 28, 2007).

21. F.R. Zimmerman, S.J. Gentz, J.B. Miller, R.A. MacKay, and M.L. Bright, "42nd AIAA/ASME/SAE/ASEE Joint Propulsion Conference \& Exhibit" (AIAA Paper 2006-4600, 2006).

22. W.A. Wong, D.J. Anderson, K.L. Tuttle, and R.C. Tew, "Proceedings of Space Technology and Applications International Forum (STAIF-2006)" ed. M.S. El-Genk, AIP Conference Proceedings.

23. Jeffrey G. Schreiber and Lanny G. Thieme, "Proceedings of Space Technology and Applications International Forum (STAIF-2008)" ed. M.S. El-Genk, AIP Conference Proceedings.

24. J. Chan, J.G. Wood, and J.G. Schreiber, "Development of Advanced Stirling Radioisotope Generator for Space Exploration," Proceedings of Space Technology and Applications International Forum (STAIF-2007), ed. M.S. ElGenk (AIP Conference Proceedings 880, 2007, (also NASA/TM-2007-214806)) 615-623.

25. I.E. Locci, J.A. Nesbitt, F.J. Ritzert, and C.L. Bowman, "Proceedings of Space Technology and Applications International Forum (STAIF-2007)" ed. M.S. El-Genk (AIP Conference Proceedings 880, 2007) 660-667. 